Global Conferences Series:

Social Sciences, Education and Humanities (GCSSSEH), Volume 6, 2020

International Conference Fakultas Tarbiyah dan Keguruan Universitas Islam Negeri Imam Bonjol Padang (ICFTKUINIBP) 2020

DOI: https://doi.org/10.32698/icftk425

\title{
Women Ulama in Forming the Concept of Female Character Education in Minangkabau
}

\section{Ulama Perempuan Dalam Membentuk Konsep Pendidikan Karakter Perempuan Di Minangkabau}

\author{
Wahyuli Lius Zen ${ }^{*} 1$, Hasnawati ${ }^{2}$ \\ ${ }^{1}$ UIN Imam Bonjol Padang, ${ }^{2}$ UIN Imam Bonjol Padang, \\ , Đe-mail: wahyuli.lius1@gmail.com, hasnawatimpd@uinib.ac.id
}

\begin{abstract}
Minangkabau women do not have a broad place to study, because women's education is only related to skills in household life carried out by the mothers or bundo kanduang in their environment. At first education in Minangkabau appeared unofficially in the form of religious education which was carried out in the surausurau, but only men could enjoy this education, during the Dutch government this classical education was still carried out but was considered illegal, so that The Netherlands inaugurated education in the form of schools, where not only men were allowed to go to school, but also women, but basically there were still many conflicts with indigenous people about women being free to enjoy education, so that only women from the aristocratic class could attend school. who can enjoy school. The education carried out and developed by ulama in Minangkabau is generally engaged in the field of religion, especially Islamic religious education, because in Minangkabau the community is more dominant with Islam and customs are more impartial and follow the rules of Islam as a philosophy of civilized life in Minangkabau, namely "Adat basandi syarak, syarak basandi kitbullah ", however, there is also education specifically given to women in Minangkabau, in this case it can be seen that the women's ulama movement in the education sector can be seen as follows: 1) In the field of Islamic Religious Education specifically for girls, 2). Education to Improve, Women's Ability, 3). Political education, 4). Journalistic education, 5), fighting for women's rights, 6), education in the field of organization, 7). Parliamentary Education, 8), Da'wah education and women's equality education.
\end{abstract}

Keywords: Women ulama, minangkabau character and women education

\section{PENDAHULUAN}

Perempuan di Minagkabau berada pada level kedua setelah kaum laki-laki, pandangan ini disebabkan oleh persepsi masyarakat Minagkabau secara turun temuru, meraka beranggapan bahwa perempuan secara adat dipandang pekerjaanya diperbolehkan hanya mengurus rumah tangga, sedangkan untuk urusan ke luar rumah dan mencari nafkah adalah kaum laki-laki, sehingga kaum perempuan pada usia bealasan tahun sudah menjadi wewenang mamak untuk menentukan urusan kehidupannya di kemudian hari. Akan tetapi secara adat perempuan Minangkabau berada diposisi yang tertinggi karena adat Minangkabau menganut Matriakat maksudnya keturunan dilihat dari keturunan ibu, yang mendapat warisan yang banyak adalah kaum perempuan hal ini terlihat dari ungkapan adat bahwa kaum perempuan merupakan bundo kanduang, dimana kaum perempuan dinyatakan bahwa perempuan mempunyai posisi yang kuat akan tetapi adat ini juga yang dimanfaatkan untuk mengekang kaum perempuan, dalam kaca mata sosial di lingkungan masyarakat Minangkabau.

Kaum perempuan dalam bidang pendidikan tidak mendapat tempat yang luas dalam menuntut ilmu, karena pendidikan perempuan hanya berkaitan dengan keterampilan dalam kehidupan berumah tangga yang dilakukan oleh kaum ibu atau bundo kanduang yang ada dilingkungan mereka. Pada awalnya pendidikan di Minangkabau muncul secara tidak resmi berbentuk pendidikan agama yang dilakukan kegiatannya di surau-

Copyright (C) 2020, the Authors. Published by Redwhite Press. 
surau, akan tetapi yang bisa menikamti pendidikan ini hanya kaum laki-laki, pada masa pemerintahan Belanda pendidikan klasik ini masih tetap dijalankan akan tetapi dianggap tidak legal, sehingga Belanda meresmikan pendidikan berbentuk sekolah, di mana tidak hanya kaum laki-laki saja yang boleh sekolah, akan tetapi perempuan juga, tetapi pada dasarnya masih banyak pertentangan dengan kaum adat mengenai perempuan boleh bebas menikmati pendidikan, sehingga yang dapat sekolah kaum perempuan dari golongan bangsawan saja yang dapat menikmati bangku sekolah.

Pendidikan penting bagi perempuan karena perempuan merupakan pelopor dalam melakukan perubahan dalam kehidupan di masa yang akan datang, perempuan merupakan tokoh pendidik yang paling dominan mempengaruhi perubahan prilaku, adat, kebudayaan dan kemajuan di masa yang akan datang. Perempuan berkiprah dalam melakukan transisi kehidupan melalui pendidikan di mulai dari lingkungan keluarga maupun masyarakat di sekitarnya. Hal ini akan mengarah kepada perwujudan tanggung jawab moral dalam melakukan pendidikan pada generasi berikutnya akan berdampak kepada perkembangan program pemerintah. Tulisan ini mengemukakan gerakan ulama perempuan di Minangkabau antara tahun 1890-1945.

Pendidikan yang akan dilihat di sini merupakan pendidikan dari pendidikan formal, in formal dan non formal yang bergerak pada pendidikan yang diberikan kepada kaum perempuan guna membangun kaumnya dan membangun bangsanya di kemudian hari.

\section{METODE}

Dalam penelitian ini, penulis menggunakan jenis penelitian kepustakaan (library reseach), yaitu serangkaian kegiatan yang berkenaan dengan metode pengumpulan data pustaka. Kepustakaan (library reseach) yaitu penelitian yang mengguunakan cara untuk mendapatkan data informasi dengan menempatkan fasilitas yang ada di perpustakaan, seperti buku, majalah, dokumen, catatan kisah-kisah sejarah. Atau penelitian kepustakaan murni yang terkait dengan objek penelitian serta pusat dokumentasi yang ada di Padang, padang Panjang, Payakumbuh, Bukittinggi dan Belanda.

\section{PEMBAHASAN}

Pendidikan yang dilakukan dan dikembangkan oleh ulama di Minangkabau pada umumnya bergerak di bidang agama khususnya pendidikan agama Islam, karena di Minangkabau lebih dominan masyarakatnya beragama Islam dan adat istiadat lebih memihak dan mengikuti aturan agama Islam sebagai filosofis kehidupan beradat di Minangkabau yaitu "Adat basandi syarak, syarak basandi kitbullah", akan tetapi ada juga pendidikan yang diberikan khusus bagi perempuan di Minangkabau dalam hal ini dapat dilihat gerakan ulama perempuan di bidang pendidikan dapat ditunjau sebagai berikut :

\section{Dibidang Pendidikan Agama Islam khusus Puteri}

Pendidikan Diniyah puteri ini memeliki beberapa program pendiidikan yang bisa diakatakan unggul, yaitu (a) Pendidikan Umum, pendidikan ini ada beberapa pembagiannya berupa kelompok pengetahuan umum, pembelajaran bahasa, dan keterampilan, (b) program pendidikan keahlian di bidang agama dan pengetahuan agama, dalam program ini sasarannya kaum perempuan dapat memahami agama dengan baik sehingga bisa mendidik generasi berikutnya berupa anak-anak mereka di rumah ke arah yang baik, serta bisa juga menjadi ahli di bidang agama dengan mengarah kepada guru agama dan da'i, (c) program pendidikan khusus.

Di samping mendirikan Diniyah School Putri, Rahmah mendirikan sebuah sekolah yang khusus bagi ibu-ibu rumah tangga yang belum pernah mengenyam pendidikan atau tidak selesai menempuh pendidikan semasa ia remaja, karena pandangan masyarakat Minangkabau menganggap bahwa pendidikan lebih diutamakan bagi kaum laki-laki, karena laki-laki dianggap sebagai orang yang pantas melakukan hal tersebut dan kaum perempuan tidak perlu dan dianggap tidak penting mengenyam pendidikan yang lebih tinggi, hal ini berdasarkan pandangan masyarakat bahwa dianggap tabu suatu keluarga apabila anak gadisnya belum juga dapat jodoh pada usia belasan tahun dan masih sibuk menggeluti pendidikan, karena menempuh pendidikan dalam pandangan masyarakat tidak penting bagi perempuan karena tidak ada manfaatnya dalam kehidupan mereka di rumah tangga.

\section{Pendidikan Untuk Meningkatkan Kemampuan Perempuan}

Salah satu program pendidikan yang didirikan oleh Rohana Kudus adalah kerajinan Amai Setia yang didirikan pada tanggal 11 Februari 1911 di koto gadang kota Bukittinggi, kegiatan pendidikan yang pertama dilaksanakan adalah program pendidikan tulis baca berupa ketrampilan membaca latin dan Arab melayu yang 
dikhususkan bagi kaum perempuan. Hal ini bertujuan agar kaum perempuan bisa melek baca dan mampu membaca dengan baik agar dapat menambah wawasan dan ilmu pengetahuan lewat membaca.

Kegiatan lainnya dalah berupa kerajinan tangan seperti jahit menjahiit, membuat kue, dan membuat aneka bunga dari kertas pelajaran ini dilaksanakan di sekolahnya yang bernama sekolah Gadis di Koto Gadang Bukittinggi. Sasaran pendidikan ini memberikan keterampilan kepada kaum perempuan dalam beberapa keterampilan yang berkaitan dengan kewanitaan, sehingga bisa diterapkan dilingkungan keluarga dan masyarakat sekitarnya, sehingga bisa menambah income rumah tanggga masing-masing. Secara umum pola pendidika yang dilaksanakan oleh Rohana kudus mengarah kepada emansipasi wanita, di mana tantanggannya memberikan kesempatan untuk kaum perempuan mengenyam pendidikan seperti kaum lakilaki.

\section{Di bidang Politik}

Hajjah Rangkayo Rohana kudus selain bergerak di bidang politik secara organisasi, juga menyalurkan politiknya lewat jurnalistik berupa menulis tentang memperjuangkan hak-hak perempuan agar mereka mampu mengembangkan potensinya dan berada pada bidang yang sejajar dengan kaum laki-laki lewat surat kabarnya sunting Melayoe. Bahkan lewat tulisannya di majalah dan surat kabar ia berani mengkritik pemerintahan kolonial Belanda dan Jepang yang telah menyengsarakan rakyat.

\section{Bidang jurnalistik}

Rasuna Said selain sebagai pendidik dan bergelut di bidang politik usahanya untuk memperjuangkan perempuan dan menyampaikan suaranya di bidang politik terutama dalam melawah penjajah dengan cara bergabung dalam kegiatan kepenulisan atau jurnalistik. Ia menempuh pendidikan di Islamic College.

\section{Memperjuangkan hak-hak perempuan}

Rohana kudus, Rahmah El Yunusiah dan Umi Salamah merupakan tokoh yang memperjuangkan hakhak perempuan dengan tujuan agar mereka mampu mengembangkan potensinya dan berada pada bidang yang sejajar dengan kaum laki-laki. Rohana kudus memperjuangkan hak-hak kaum perempuan dalam bentuk tulisannya di surat kabar Soenting melajoe, di sini banyak keterampilan yang dapat didapat dilakukan oleh kaum perempuan dalam kehidupan sehari-hari, pembahasan sekitar hak dan potensi perempuan yang bisa dikembangkan, di mana selama ini kaum perempuan tidak mengenal kemampuan dan potensinya yang tersembunyi dan sebenarnya dapat digunakan dalam memperbaikan tatanan kehidupannya di masa yang akan datang serta beberapa permasalahan yang dapat diatasi seputar masalah perempuan permasalahan dalam kehidupannya yang dapat diselesaikan tanpa ada bantuan dari kaum laki-laki, atau tanpa menunggu keputusan dan tindakan yang diambil dari kaum laik-laki.

\section{Bidang Organisasi}

Rohana kudus memilih masuk organisasi Persatuan Muslimin Indonesia (PMI atau Permi) pada tahun 1930. Permi didirikan oleh perhimpunan "Sumatra Thawalib" atau murid-murid Sumatera dibawah naungan Sekolah Thawalib. Rasuna Said dengan demikian menjadi anggota dari dua organisasi yang berbeda yaitu Sarekat Rakyat dan Permi. Ia dikenai peraturan disiplin partai karena menjadi anggota diluar Sarekat Rakyat. Ia pun harus memilih salah satu, kemudian diputuskan bahwa ia tetap menjadi anggota Permi, dengan kata lain keluar dari PSII. Rasuna Said aktif memberikan kursus-kursus seperti berpidato dan latihan berdebat. Berkat kepiawaiannya, ia menjadi satu-satunya.

\section{Dibidang Parlemen}

Rasuna Said mengawali perannya di Parlemen dengan keikutsertaannya dalam Panitia Pembentukan Dewan Perwakilan Nagari. Hasil dari pembentukan panitia tersebut, terbentuklah Dewan Perwakilan Sumatera (DPS) pada tanggal 17 April 1946. Rasuna Said yang masih tergabung dalam Komite Nasional Indonesia Daerah Sumatera Barat (KNID-SB), mengikuti sidang pleno yang ke delapan pada tanggal 4 sampai 6 Januari 1947. Sidang tersebut membahas tentang pemilihan anggota untuk Komite Nasional Indonesia Pusat (KNIP) yang akan ditempatkan di Jakarta. Berdasarkan seleksi yang ia ikuti, dirinya terpilih untuk menjadi anggota KNIP. Rasuna Said bergabung pula dalam Front Pertahanan Nasional sebagai Seksi Wanita bagian logistik.

Keberadaannya yang jauh dari tanah kelahiran bukan berarti membuat Rasuna Said kehilangan semangat juangnya dalam menyuarakan hak-hak perempuan Minang. Dirinya merupakan delegasi putri asal Sumatera Barat yang terpilih untuk mewakili kaum perempuan dalam KNIP, hal ini tentu menjadi suatu kebanggaan bagi kaumnya. Rasuna Said kembali dipercaya untuk memangku jabatan yang lebih tinggi di 
kancah perpolitikan. Pasca diselenggarakannya Konferensi Meja Bundar (KMB) tahun 1949 di Den Haag,( Nidia ,2011).

\section{Dibidang dakwah}

Syamsidar meniti kariernya sebagai guru di sekolah Thawalib Putri di Maninjau. Sekolah itu adalah \&asi dari Dinyah Putri Padangpanjang. Dengan demikian hubungannya dengan gurunya, Ibu rahmah El Yunusiayh tidaklah terputus sama sekali. Malahan bertambah dekat dan menjadikannya sebagai mentor politiknya. Di samping menjalani profesi guru, Syamsidar muda juga aktif berdakwah. Ia seroang remaja cerdas dan memiliki bakat sebagai ahli pidato dan penceramah agama yang disenangi oleh jemaah pengajian. Kegiatan ini baginya sekaligus menjadi kendaraan untuk bepergian dan berhubungan dengan kaum pergerakan. mulai meniti kariernya sebagai guru di Maninjau sambil berdakwah. Sejak itu ia mulai dikenal sebagai pembicara yang menarik dan disukai ummat. (Mestika Zed, 2010).

\section{Dibidang Kesetaraan Perempuan}

Hj. Syamsiyah Abbas sebagai ulama perempuan di kalangan Perti. Hj. Syamsiyah Abbas ternyata mampu mengambil peran yang selama ini hanya diisi oleh kaum laki-laki. Hj. Syamsiyah Abbas mengambil peran yang sangat besar dalam MTI, mulai dari mendirikan, memimpin jalannya lembaga, sampai terjun langsung menjadi tenaga pengajar atau guru. Langkah yang diambil ummi Syamsiyah terbilang cukup berani dan progresif di zamannya. Ia membuktikan bahwa perempuan itu bukanlah kaum yang cengeng, lemah dan selalu menjadi nomor dua.

Semangat untuk mengangkat harkat kaum muslimah ini rupanya telah terpatri dengan mendapat landasan yang kokoh dalam ajaran Islam yang secara tegas menyebutkan: "Menuntut ilmu itu wajib bagi tiaptiap orang Islam laki-laki dan perempuan". Jika kaum perempuan tidak mendapatkan ilmu yang memadai, maka bahaya akan datang dalam lingkungan masyarakat. Namun jika pendidikan yang diberikan kepada mereka itu keliru, maka tidak sedikit pula malapetaka yang akan menimpa bagi segenap masyarakat manusia. (Syamsudin arif, 2008).

\section{KESIMPULAN}

Pendidikan yang dilakukan dan dikembangkan oleh ulama di Minangkabau pada umumnya bergerak di bidang agama khususnya pendidikan agama Islam, karena di Minangkabau lebih dominan masyarakatnya beragama Islam dan adat istiadat lebih memihak dan mengikuti aturan agama Islam sebagai filosofis kehidupan beradat di Minangkabau yaitu "Adat basandi syarak, syarak basandi kitbullah", akan tetapi ada juga pendidikan yang diberikan khusus bagi perempuan di Minangkabau dalam hal ini dapat dilihat gerakan ulama perempuan di bidang pendidikan dapat ditunjau sebagai berikut : 1) Dibidang Pendidikan Agama Islam khusus Puteri, 2). Pendidikan Untuk Meningkatkan, Kemampuan Perempuan, 3). Pendidikan politik, 4). Pendidikan jurnalistik, 5), memperjuangkan hak-hak perempuan, 6), pendidikan Bidang organisasi, 7). Pendidikan Bidang parlemen, 8), Pendidikan dakwah dan pendidikan kesetaraan perempuan.

\section{REFERENSI}

Darwis, Yiliandre, (2009). Sejarah Perkembangan Press Minangkabau (1859-1945), Jakarta ,PT Gramedia Pustaka

Djaja,Tamar. (1980). Rohana Kudus Srikandi Indonesia Riwayat Hidup Dan Perjuangannya, Jakarta, Mutiara

Febri Yulika. (2012). Epistemologi Minangkabau: Makna Pengetahuan dalam Filsafat Adat Minangkabau, Yogyakarta: Gre Publishing

Gillian Howie. (2010). Between Feminism and Materialism: A Question of Method, New York: Palgrave Macmillan,.

Graves, Elizabeth e. (2007). Asal Usul Elite Minangkabau Modern Respon Terhadap Belanda Abad XIX/XX, Jakarta

Jawad, Haiffa A. (1998). The Rights of Women in Islam:an Authentic Approac. New York: ST Martin's Press, Inc.

Mansour Fakih, et.all. (2000). Membincang Feminisme: Diskursus Gender Perspektif Islam, Surabaya: Risalah Gusti,

Nidia Zuraya. (2011). “Membangun Kemandirian Perempuan”, Republika. 
Nunuk P. Murniati. (2004). Getar Gender: Perempuan Indonesia dalam Perspektif Sosial, Politik, Ekonomi, Hukum, dan HAM, Jilid 1, Magelang: IndonesiaTera, hlm. xxviii.

Nuruddin 'Itr. (2005). Hak dan Kewajiban Perempuan: Mempertanyakan Ada Apa Dengan Wanita?, Yogyakarta: Bina Media,.

Pengurus Perguruan Diniyah Putri. (1991). Hajjah Rahmah El Yunusiyyah Dan Zainuddin Labay El Yunusy Dua Bersaudara Tokoh Pembaharu System Pendidikan Di Indonesia, Jakarta

Rasyad, Aminuddin. (1978). Rahmah El Yunusiyah, Kartini dari Perguruan Islam, dalam "Manusia dalam Kemelut Sejarah." Lembaga Penelitian Pendidikan dan Penerangan Ekonomi dan Sosial. Jakarta.

Syamsuddin Arif. (2008). Orientalis dan Diabolisme Pemikiran, Jakarta: Gema Insani

Tuanku Kayo Khadimullah. (2007). Menuju Tegaknya Syariat Islam di Minangkabau: Peranan Ulama Sufi dalam Pembaharuan Adat, Bandung: Marja.

Zed, Mestika. (2010). Biografi Hj, Rangkayo Syamsidar Yahya Tokoh Perempuan dari Sumatera, Padang Pusat Kajian Sosial, budaya dan ekonomi FSIP UNP

Zubir, Zusneli. (2011). Perjalanan Tokoh Perempuan Minangkabau Menantang Tradisi, Jakarta, Eja Publisher 